\title{
FORMAS DE APROPRIAÇÃO DE CONCEPÇÕES DE BAKHTINNOLOCHINOV POR ESTUDOS ACADÊMICOS EUROPEUS CONTEMPORÂNEOS
}

Ana Zandwais*

RESUMO: Este estudo, desenvolvido na Universidade Federal do Rio Grande do Sul, busca investigar formas de apropriação de algumas concepções produzidas por Bakhtin/Volochinov, tais como polifonia, ideologia e sentido. Nossa meta consiste em mostrar como pesquisas contemporâneas desenvolvidas no contexto europeu podem contribuir para colocar em evidência aspectos incongruentes entre concepções formuladas por Bakhtin/Nolochinov e pressupostos teóricos desenvolvidos fora do contexto soviético/russo.

PALAVRAS-CHAVE: Polifonia; enunciação; sentido.

INTRODUÇÃO

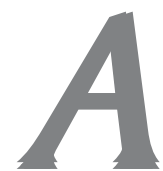

través deste estudo buscamos caracterizar modos de apropriação e de reformulação/apagamento das concepções bakhtinianas inscritas em estudos acadêmicos produzidos na atualidade por linguiistas europeus. Para fins específicos deste artigo, propomo-nos a analisar como o arcabouço teórico produzido pelo Círculo de Bakhtin tem servido de fonte às pesquisas desenvolvidas, na França, por Oswald Ducrot e Jacqueline Authier-Revuz.

Universidade Federal do Rio Grande do Sul. 


\section{A HETEROGENEIDADE DE UM CONTEXTO DE PESQUISA: FORMAS DE APROPRIAÇÃO DE CONCEPÇÕES INTRODUZIDAS POR BAKHTIN/ VOLOCHINOV}

A problemática sobre os efeitos produzidos em torno de diferentes modos de apropriação de conceitos elaborados por Bakhtin/ Volochinov não é recente, e, conforme Sériot (2005), os escritos desses autores "têm recebido enfoques bastante diferentes de acordo com os lugares e as épocas de interpretação". Ainda, segundo Sériot (2005, p. 60), se os estudos produzidos pelo Círculo de Bakhtin têm sido representados, "desde a perspectiva dos pesquisadores do "Oeste" por um "movimento da morte do autor, atravessado por um discurso que se sustenta em torno das noções de alteridade e heterogeneidade", os estudos produzidos no "Leste" buscam situar-se, fundamentalmente, em relação ao corte epistemológico produzido por Bakhtin/Volochinov contra a soberania dos estudos formalistas e estruturalistas dominantes no contexto soviético.

Conforme Sériot ${ }^{1}$ (2005, p. 42), se na Rússia os conceitos do Círculo de Bakhtin têm sido vistos como objetos de "pensamentos não oficiais", desenvolvidos de forma isolada da produção acadêmica da época, sufocada durante a hegemonia stalinista, tendo estes sido mais aproximados da vertente filosófica continental ou européia, de acordo com Tchougounnikov (2005), ${ }^{2}$ as concepções do Círculo foram redesenhadas à luz da filosofia marxista, adquirindo novos contornos. Desse modo, conceitos como ideologia, signo ideológico, ideologema, refração, corpo material, corpo social, consciência interior, consciência exterior foram determinantes à especificidade que adquiriram as questões filosóficas sobre a linguagem no contexto soviético, na medida em que foram reinterpretadas

1 Em um trabalho intitulado Bakhtin no Contexto: diálogo de vozes e hibridação das línguas (o problema dos limites), Sériot (2005) aborda essa questão, colocando em perspectiva as diferentes interpretações dos escritos do Círculo de Bakhtin nos contextos de investigação do "Leste e Oeste" europeus.

2 Segundo Tchougounnikov (2005), as bases da Filosofia da Linguagem soviéticas teriam sofrido influências, sobretudo dos fundamentos da filosofia alemã. 
sob a ótica antipositivista e materialista histórica de Bakhtin/ Volochinov, influenciando, desse modo, os rumos antiformalistas que a Filosofia da Linguagem iria seguir, inclusive no contexto ocidental.

Assim também não é sem razão que Michel Pêcheux, em seu um célebre texto intitulado "Remontémonos de Foucault a Spinoza" e publicado em Tesis de Amiens (1976), apresenta a seguinte apreciação em torno dos estudos discursivos produzidos no contexto soviético e retomados na França por historiadores, filósofos, linguiistas e até mesmo estadistas:

Língua, ideologias e discurso: nem Marx, nem Lênin, nem um dos chamados "clássicos do marxismo" produziu um estudo organizado politicamente sobre este tema. Os pensadores do marxismo-leninismo detiveram-se, a este respeito, em observações de ordens muito genéricas, de modo que, desde Volochinov até nossos dias, pode-se dizer que esta questão tem sido e segue sendo coisa de universitários progressistas (poucos linguiistas, historiadores e filósofos sobretudo). (Pêcheux, 1980 , p. 181$)^{3}$

Tais observações vêm também ao encontro das considerações feitas pelo lingüista russo Abaev em um estudo intitulado Modernismo e desumanização da linguiística ${ }^{4}(1969$, p. 7$)$ em torno da diversidade de preocupações dos lingüistas europeus e soviéticos acerca do funcionamento da linguagem:

\footnotetext{
Aqueles que se ocupam com a língua de modo apartado da história se ocupam, de fato, não da língua mas de uma ficção que não encontra correspondência em nenhuma realidade objetiva.
}

A luta contra a desumanização da cultura é uma das tarefas mais importantes dos intelectuais de vanguarda no mundo inteiro. A Linguiística é

3 Fazemos referência à tradução em língua espanhola do estudo de Pêcheux, publicado em El discurso político. México: UNAM/Editorial Nueva Imagem, 1980, p. 181-97.

4 O título original do referido trabalho publicado em Langages: la linguistique soviétique en URSS é Modernisme et déshumanisation de la linguistique. 
ZANDWAIS, Ana. Formas de apropriação de concepções de bakhtin/volochinov...

um destes setores de combate. Mas este setor se torna importante somente se levarmos em conta o papel excepcional da língua na vida da sociedade e na história da cultura. Os lingüistas soviéticos devem continuamente lembrar-se da importância do setor em que se ubicam. (ibid., p. 8)

Cabe observar, por outro lado, que não obstante o contexto de pesquisas ocidental tenha sido caracterizado por Sériot (2005) como um contexto que, sobretudo, dá ênfase às questões de alteridade e heterogeneidade -"simbolismos da morte da autoria" -, nossas incursões por produções científicas ocidentais, colocando em relevo o contexto europeu, têm nos mostrado que tal movimento exegético parece, não raro, passar por um processo de "globalização" dos conceitos de Bakhtin/Volochinov, o que, segundo nosso ponto de vista, resulta muitas vezes em apagamentos de princípios epistemológicos que redundam, em última instância, em um trabalho de "formalização mais ou menos liberal" das concepções filosóficas desenvolvidas por Bakhtin/Volochinov, sobretudo em Marxismo e filosofia da linguagem (1986).

É, pois, a partir de uma análise de concepções de polifonia e heterogeneidade, formuladas por Oswald Ducrot (1987) e AuthierRevuz (1998), alicerçadas em pressupostos da teoria de Bakhtin/ Volochinov, que buscaremos situar nossa investigação, na tentativa de delimitar algumas formas de apropriação/desapropriação das concepções ideologia e polifonia.

No contexto em que nos propomos a delinear esse diálogo entre os pensamentos do "Leste e do Oeste", buscaremos dar destaque às perspectivas através das quais o sujeito é descentrado nos estudos europeus e sob que aspectos algumas concepções de polifonia e de heterogeneidade discursiva promovem rupturas com as bases dos estudos estruturalistas, mas também reduzem pressupostos dos materialismos histórico e dialético, descrevendo a materialidade discursiva como um regime de materialidades enunciativas tomadas da própria língua, enquanto um conjunto de sistematicidades; enfim, um espaço em que os sentidos são descritos em seu funcionamento, e formalizados para que dêem visibili- 
dade às formas heterogêneas sob as quais a enunciação qualifica os enunciados, mas que, por outro lado, possibilita a dominância de regimes enunciativos marcados estruturalmente, em detrimento de suas condições sócio-históricas de produção e circulação.

\section{1. A concepção polifônica de Oswald Ducrot}

Em uma de suas principais investigações sobre o funcionamento da polifonia na linguagem, intitulada Esboço de uma teoria polifônica da enunciação, Oswald Ducrot (1987) propõe-se a contestar o pressuposto da unicidade do sujeito que, segundo ele, tem sido dominante entre as teorias comparatistas, estruturalistas e gerativistas. Segundo o autor, tal pressuposto também dominaria os estudos literários que, tradicionalmente, tratariam da perspectiva dialógica emergente do estilo indireto-livre como um fenômeno de fluxo de consciência. Para ilustrar sua discordância em relação às tendências equivocadas de pesquisadores sobre questões de estilo na literatura, Ducrot (1987, p. 162) reporta-se ao estudo de Ann Banfield (1979) em torno do estilo indireto-livre, como uma das formas de discurso relatado, criticando Banfield por designar de "sujeito de consciência" o autor de um determinado ponto de vista e, ao mesmo tempo, por identificá-lo como um sujeito uno, autor empírico dos enunciados formulados em discurso indireto-livre, conforme ilustramos a seguir, através dos comentários de Ducrot:

\footnotetext{
Não censurarei Banfield por distinguir o locutor, ou seja, o ser designado no enunciado como seu autor (através de marcas de primeira pessoa)[..]. O que censurarei em Banfield é a motivação que a leva a esta distinção, a saber, o cuidado em manter, a qualquer preço, a unicidade do sujeito falante... (Ducrot, 1987, p. 161)
}

Desse modo, para elaborar sua teoria sobre a não-unicidade do sujeito, como sendo constitutiva da linguagem e do sentido, Ducrot (1987, p. 161), reporta-se a Bakhtin, observando que "para este autor há toda uma categoria de textos, e, notadamente, de textos literários, para os quais é necessário reconhecer que várias 
vozes falam simultaneamente, sem que uma dentre elas seja preponderante e julgue as outras". Trata-se do que Bakhtin chama, por oposição à literatura clássica ou dogmática, de literatura popular, qualificada, às vezes, segundo Ducrot, como mascarada, já que, de acordo com o ponto de vista de Ducrot, para Bakhtin, o autor assume uma série de máscaras diferentes. E com vistas a explicitar os pressupostos que adota, Ducrot observa que sua teoria da polifonia pode ser vista como uma "extensão livre" dos trabalhos de Bakhtin, estando, sobretudo, ancorada nas pesquisas de Authier (1978) e Plenat (1975). ${ }^{5}$

A fim de apresentar seus postulados a respeito do funcionamento da polifonia, Ducrot (1987, p. 161) comenta, então, o que segue: "esta teoria de Bakhtin, segundo meu conhecimento, sempre foi aplicada a textos, ou seja, a sequiências de enunciados, jamais aos enunciados de que estes textos são constituídos. De modo que ela não chegou a colocar em dúvida o postulado segundo o qual um enunciado faz ouvir uma única voz”.

É, pois, com base em tais pressupostos que Ducrot (1987, p. 168) passa a definir a enunciação como "o acontecimento constituído pelo aparecimento de um enunciado", considerando a realização de um enunciado como "um acontecimento histórico", em virtude do fato de ser dada existência "a alguma coisa que não existia antes de se falar e que não existirá mais depois” (ibid., p. 168). Desse modo, conforme se pode observar, a enunciação, para Ducrot, consiste em um acontecimento histórico, não em virtude das determinações anteriores e exteriores que a afetam, mas como um ato de fala tomado, notadamente, em sua temporalidade e singularidade, isto é, como um ato ilocutório reduzido à sua dimensão espaçotemporal única, sendo o sentido, para ele, "uma descrição, uma qualificação da enunciação" (ibid., p. 172).

Ducrot (1987) reporta-se aos artigos "Les formes du discours rapporté", de Jacqueline Authier-Revuz, e "Sur la grammaire du style indirect libre", de Plenat. 
A partir de tais princípios, segundo o autor, "o objeto próprio de uma concepção polifônica de sentido consiste em mostrar como o enunciado assinala, em sua enunciação, uma superposição de vozes" (ibid., p. 172). Desse modo, segundo Ducrot, uma das razões que o motiva a tratar a enunciação como um ato constituído por múltiplos sujeitos é a existência, para certos enunciados, de uma pluralidade de responsáveis, dados como distintos e irredutíveis (ibid., p. 182). É, pois, desde essa perspectiva que Ducrot caracteriza o locutor como sendo responsável pelo dito e o diferencia da fonte do dizer ou da abstração que o sujeito falante faz dessa fonte, passando a definir os enunciadores como "seres que se expressam, sem que para tal lhes sejam atribuídas palavras precisas”. Para ele, os enunciadores falam "no sentido em que a enunciação é tomada como expressão de seu ponto de vista, sua posição", e que não se traduz de forma transparente, mas somente através de um jogo de dizeres imputados aos locutores, os quais se transvestem do papel de responsáveis pelo dito.

Assim, o enunciado, considerado uma "qualificação da enunciação", ou seja, se visto a partir das condições em que o dizer se produz, passa a atestar, em seu interior, tanto combinações de perspectivas que se assimilam, como perspectivas que se conflitam, refletindo, em última instância, o modo como a enunciação pode jogar com contradições e antagonismos no discurso, sem que se evidenciem marcas linguíísticas para tal, colocando, ao mesmo tempo, sob tensão a emergência de uma ou outra perspectiva em detrimento das demais. É, pois, a partir desse jogo de assimetria entre o dito (aquilo que os enunciados qualificam através de seus locutores) e as condições que possibilitam qualificá-los, que se produzem, para Ducrot, os sentidos, enquanto efeitos de perspectivas que dominam os discursos. Cabe, portanto, ao enunciado, enquanto materialidade da enunciação, colocar em cena as representações de uma rede complexa de dizeres que, imbricados uns aos outros, não necessariamente devem assimilar-se. 
Ilustremos a questão através de enunciados de negação ${ }^{6}$ que retomam outras vozes. Em um processo de sufrágio, um proferimento como: (1) "O Partido X é um tanto 'conservador' para governar, irá deixar as coisas simplesmente como estão"; pode ser mobilizado por um eleitor (L2), a fim de refutar a perspectiva de outros eleitores (L1) que são favoráveis à eleição de candidatos do Partido X. Assim, em "O Partido X é um tanto 'conservador' para governar”, o locutor (L2) não somente nega, através da afirmação, o ponto de vista de (L1), de que o Partido X teria condições de assumir o poder, mas também demonstra seu descontentamento com a política adotada pelo Partido, para classificá-lo como inapto. Do mesmo modo, um enunciado como (2) "O Partido X não é corrupto, expulsa os políticos que promovem escândalos e praticam o nepotismo"; se proferido por um seu militante (L2), coloca em evidência uma perspectiva que nega tanto a corrupção enquanto prática político-partidária, como as acusações anteriormente feitas por adversários (L1), dissidentes (L3), enfim outras vozes dissonantes da política do Partido X. Assim, ao inscrever em seus enunciados perspectivas antagônicas, L2 fortalece a posição de que X é um Partido que não adere à corrupção.

Dada a importância das contribuições de Ducrot para desconstruir tanto a evidência da unicidade do sujeito, como a evidência da simetria entre o dizer e os sentidos que este coloca em jogo através da enunciação, faz-se mister destacar alguns pontos que merecem relevância em sua teoria.

a) Ao questionar a unicidade do sujeito, partindo de uma leitura crítica da noção de "sujeito de consciência", desenvolvida nos estudos literários, Ducrot desconstrói, ao mesmo tempo, as evidências da homogeneidade da enun-

6 Cabe observar que desde uma perspectiva enunciativa, o proferimento de negação não necessita de estrutura canônica, já que o ato de negar o dizer de outrem escapa à ancoragem da materialidade linguiística. 
ciação e descentra a ilusória concepção de unidade do objeto discursivo.

b) Ao tratar da enunciação como um acontecimento discursivo, da ordem do irrepetível, o autor passa a tratar do sentido, não mais como um mero efeito da materialidade linguiística, mas como um efeito de determinadas condições que mobilizam a estrutura, movimentando-a de acordo com posições assumidas pela enunciação ou representadas por topöi (lugares de onde se fala), de acordo com a terminologia adotada por Aristóteles em sua célebre obra Tópicos (1987), ${ }^{7}$ da qual Ducrot se apropria para colocar em evidência o fato de que o sentido sempre deriva do lugar a partir do qual se enuncia, não podendo, por isso, ser questionado em termos de verdade ou falsidade.

c) É através da noção de sujeito fragmentado, tomada de Bakhtin, que o autor abre um espaço, por meio de sua descrição semântica, para o tratamento das condições que possibilitam caracterizar o funcionamento da heterogeneidade da enunciação, concepção investigada de modo específico por Authier-Revuz (1998), e na qual ele afirma também haver-se inspirado.

Faz-se necessário, entretanto, considerar, a partir das observações acima feitas, alguns limites em torno do modo de apropriação, feito por Ducrot, das concepções filosóficas de linguagem propostas por Bakhtin/Volochinov (1986).

Se este autor desconstrói a unicidade do sujeito, configurando o discurso como um espaço de dispersão de vozes tomadas no acontecimento enunciativo, a partir de lugares de dizer determinados (topöi), obscurece também o fato de que os lugares de enunciação, as perspectivas que se assimilam ou que se contraditam em

7 Trabalhamos com a edição portuguesa de Tópicos, traduzida por Pinharanda Gomes. 
um discurso estão determinadas por outro espaço de dispersão: o espaço histórico das contradições vividas entre as classes sociais. É nesse aspecto, sobretudo, que ele apaga a concepção de ideologia que permite a Bakhtin/Volochinov tomar a fragmentação dos sujeitos como um efeito da divisão do modo de produção das relações de produção e, portanto, da própria ordem desigual da sociedade, que representa a ordem do real, segundo os conjuntos de interesses dominantes nas conjunturas superestruturais. Assim, ao refratar pressupostos histórico-materialistas propostos na teoria de Bakhtin/Volochinov, Ducrot passa a apagar, em consequiência, o fato de que as múltiplas vozes que povoam a enunciação, representando diferentes lugares sociais, não se criam "espontaneamente" na instância do acontecimento enunciativo, mas, ao contrário, refletem as injunções das condições históricas que determinam suas possibilidades de amalgamação.

Outro fator reducionista dessa teoria, cabe destacar, consiste no fato de que ao pensar a instância da presença da palavra de um na palavra do outro, dentro do acontecimento enunciativo, Ducrot também apaga a noção de chronotopos, formulada por Bakhtin (1990) a fim de caracterizar o acontecimento do enunciado como um ponto em que o tempo e o espaço tornam-se transversos, enfim, para colocar em evidência o fato de que a história tem materialidades de várias ordens que permitem apreender as condições de produção e sedimentação de fatores ideológicos. Essas materialidades, em sua relação transversa, permitem atestar a dominância de determinados comportamentos sociais em detrimento de outros, através do modo como as práticas sociais, tomadas em seus diferentes contextos de produção, são discursivizadas. Cabe salientar que, para Bakhtin (1990), a relação transversa entre o tempo e o espaço determina as formas através das quais os rituais e as práticas sociais adquirem prestígio e se discursivizam, deixando marcas nos modos como os sujeitos significam a realidade externa, e subjetivam-se a partir desta. Assim, ao incorporar em suas formas de expressão a palavra do outro, os sujeitos incorporam, sobretudo, sentidos que 
atestam as formas de inscrição e circulação de valores simbólicos engendrados em relações espaço-temporais. Eis que a ideologia tem história e materialidades concretas de diferentes ordens.

Ducrot, por outro lado, ao caracterizar a relação espaço-temporal como fator de "individualização", de qualificação dos enunciados, perde de vista o fato de que os enunciados tomados em seus acontecimentos são sempre relativizados em favor do modo como as forças dominantes das culturas em permanente pulsão e contradição, articuladas sob relações espaço-temporais complexas, podem reformular e atualizar os acontecimentos. Assim, as apropriações do discurso de outrem, "na vida concreta" expressam a complexidade múltipla dos sentidos que estão em jogo em diferentes momentos históricos nos quais os sujeitos se inscrevem. Ao elidir, portanto, tais questões no interior de sua teoria, Ducrot acaba elidindo a própria relação de não-coincidência entre as formas do dizer e as condições de emergência/refração dos sentidos no processo de apropriação do dizer de outrem.

\subsection{A Concepção de heterogeneidade proposta por Authier-Revuz}

Com vistas ao desenvolvimento de um estudo em torno das relações que tangenciam a língua e a exterioridade, Authier-Revuz (1998) privilegia o tratamento das formas "linguiísticas ou discursivas" (ibid., p. 14) que se configuram, segundo ela, como auto-representativas do dizer, articulando-se/desdobrando-se em múltiplas vozes. É o que a autora designa de heterogeneidade.

Para ela, entretanto, as concepções que ou "diluem" o objeto língua, reduzindo-o meramente ao social e obliterando o tratamento de suas estruturas, ou conferem ao objeto linguiístico uma autonomia de "objeto total" não estão aptas para abordar o campo enunciativo, já que este impõe uma relação obrigatória entre língua e exterioridade, a fim de que possam ser investigadas as formas de "auto-representação" do dizer. 
Desse modo, a fim de dar sustentação aos seus procedimentos analíticos, Authier-Revuz busca embasamentos teóricos em autores como Pêcheux (1988), Lacan (1966) e Bakhtin/Volochinov (1986), ${ }^{8}$ observando que da teoria de Pêcheux toma como pressupostos as noções de discurso e, sobretudo, de interdiscurso, em que o sujeito, isto é, o efeito-sujeito não se produz como um "reflexo direto" do real do processo enunciativo (ibid., p. 17). Desde essa perspectiva, para Authier-Revuz, o sujeito não é "senhor" dos domínios de seu sentido, não é a fonte de seu dizer, mas efeito das condições que o determinam.

Já da teoria de Lacan (1966), a autora toma o princípio da clivagem como central, isto é, o sujeito passa a ser produzido pela linguagem como estruturalmente clivado pelo inconsciente, o que vem corroborar a hipótese de não-transparência dos sentidos nos domínios da enunciação. Ainda, segundo a autora, através da categoria lacaniana de imaginário, que coloca em jogo a divisão que afeta o sujeito, é que se pode situar um estudo sobre as condições em que os sentidos opacificam-se/refletem-se através de diferentes modalidades de enunciação, traduzindo um imaginário do real irrepresentável por si mesmo como sendo "radicalmente heterogêneo à ordem simbólica de captura do objeto pela letra”, de separação entre o real da língua e o real do sentido, como se fosse um equívoco estruturante e inspirando, por outro lado, as diferentes versões do "mal-dizer" (2004, p. 54) como a falta, a ausência, a impropriedade.

De Bakhtin/Volochinov, a autora (id., p. 22) toma o princípio da não-coincidência do discurso consigo mesmo, considerando, a partir desse princípio, que "toda palavra, por se produzir no meio do 'já dito' dos outros discursos, é constituída pelo dizer do outro, e, ao mesmo tempo, mobiliza esse dizer". Dessa forma, é com base

8 Reportamo-nos às datas de publicação de Semântica e discurso (1988) e Marxismo e filosofia da linguagem (1986), em edições brasileiras. 
nos pressupostos da teoria bakhtiniana ${ }^{9}$ que Authier-Revuz evoca, conforme Sériot (2005), o princípio da "morte da autoria" e que, simultaneamente, será reinterpretado por filósofos marxistasleninistas como Pêcheux (1988) e Althusser (1995), através das noções de interpelação e esquecimento.

Esse aspecto fundamental, salientado por Authier-Revuz (1998), em torno da obra de Bakhtin/Volochinov, coloca em perspectiva os espaços de "partilha" que a palavra pode ocupar no discurso, em virtude de suas propriedades ideológicas, pois não sendo o terreno da palavra um "terreno natural" e sim inscrito em determinações sócio-históricas, aquilo que ela admite como seu objeto de "partilha" é o reconhecimento comum de valores que a palavra sedimenta em um "sítio ideológico". Desse modo, de acordo com Authier-Revuz, todo discurso se reporta a outros discursos que se configuram como seu exterior constitutivo. É com base nesse princípio que Authier-Revuz dá destaque ao estranhamento entre os múltiplos e contraditórios valores que as palavras representam/apresentam a partir de sua inscrição em "sítios ideológicos" distintos. Assim, para a autora (2004, p. 36), a pluriacentuação fornece à palavra acentos contraditórios que se cruzam no seu interior, no/pelo entrecruzamento dos discursos. Cabe salientar, ainda, que ao tratar das condições de possibilidade de partilha do dizer, Authier-Revuz busca, ao mesmo tempo, uma das concepções centrais da teoria de bakhtiniana; isto é, a condição de polissemia como sendo essencialmente constitutiva do signo linguiístico, e que lhe garante a propriedade de ser ideológico, remetendo o estatuto do sentido, não simplesmente para a

9 Cabe dar destaque ao fato de eu Authier-Revuz (1998) refere-se, geralmente, aos escritos contidos em Marxismo e filosofia da linguagem como sendo de autoria de Bakhtin. Entretanto, como não está em jogo o questionamento da "paternidade individual" da obra, nesse estudo, e considerando que a produção teórica deste autor se realizou em torno de um coletivo, posteriormente intitulado "O Círculo de Bakhtin", mantemos a dupla referência aqui, resguardando a sua individualidade apenas nos estudos realizados por Ducrot, já que este faz referências exclusivas à autoria de Bakhtin. 
exterioridade, mas para um "lugar de referência" determinado, um lugar próprio de interiorização da exterioridade.

É esse princípio, segundo nosso ponto de vista, que permite a Authier-Revuz abordar as relações entre o dizer e os sentidos como relações de não-coincidência, dois processos estranhos entre si, mas que, sendo inevitavelmente inseparáveis, possibilitam um entendimento sobre a condição opacificante do funcionamento da enunciação e de sua heterogeneidade. Assim, para Authier-Revuz, se os discursos apresentam as realizações mais diversas de apropriação de posições enunciativas é porque são simultaneamente afetados pela presença de outros discursos e pela não-coincidência entre sentidos já cristalizados, sentidos que deslizam e sua correspondência com os significantes. Em consequiência, a não-coincidência das palavras consigo mesmas permite caracterizar o jogo de equivocidade que trabalha os sentidos de forma permanente, como, por exemplo, através dos chistes, dos jogos lúdicos, dos torneios poéticos, das paródias, dos discursos satíricos, das réplicas, enfim, através de diferentes processos nos quais as palavras significam pelo viés do deslizamento, da estranheza e da multiplicidade.

Com base nas considerações acima, torna-se, ainda, sem dúvida, imprescindível dar destaque às noções de heterogeneidade constitutiva e mostrada, propostas por Authier-Revuz, e que representam um ponto de articulação entre a noção de polifonia, elaborada por Bakhtin/Nolochinov, e a condição de descentramento do sujeito.

Cabe salientar, também, que ao tratar com a fragmentação do sujeito na perspectiva do interdiscurso (heterogeneidade constitutiva) e no "fio do discurso" (heterogeneidade mostrada), AuthierRevuz dá um passo à frente, em relação à proposta de Ducrot, em termos de formalização dos diferentes modos por meio dos quais o sujeito é dividido diante de sua própria enunciação, através da elucidação de diferentes marcas formais que atestam essa divisão, tais como discursos direto, indireto, indireto-livre, aspas, itálico, parênteses, menções, estruturas de ratificação, reformulação etc. 
Por outro lado, não se pode deixar de observar que, ao tratar das formas de auto-representação do dizer, como heterogeneidades constitutiva (não atestadas formalmente) e mostrada (marcadas estruturalmente), Authier-Revuz aproxima-se muito mais de um projeto de formalização da modalidade linguiística de apresentação do enunciável - a heterogeneidade mostrada -, tratada no "fio do discurso", do que propriamente da heterogeneidade constitutiva. Essa questão torna-se fundamental para nós por permitir-nos colocar em evidência o fato de que se Bakhtin/Volochinov, ao tratar com uma concepção de polifonia, tomam como alicerce para suas investigações as formas de orientação das palavras, a partir de influências das "forças sociais organizadas" sobre os modos de produção/ apreensão dos discursos". Isso porque, ao tratar de todo dizer como uma "função responsiva", dialógica, em que a palavra de todos pode habitar a palavra de cada um, recobrindo múltiplos sítios ideológicos, não estão simplesmente colocando em evidência a condição de divisão da palavra em diferentes esferas de alteridade, nem buscando simplesmente atar ao "fio do discurso" essas formas de divisão do sujeito. Para eles, as relações entre o enunciável e a exterioridade estão sempre na dependência de que se possa historicizar a enunciação, da possibilidade de tomá-la em relação às "posições de referência" sócio-históricas, das quais emana, de tal modo que "todas as formas de objetivação históricas e diferençadas da ordem do real estão determinadas pelas relações contraditórias de articulação entre as ordens super e infraestruturais que engendram os diferentes modos de produção das sociedades em cada época. É a partir dessa perspectiva epistemológica, pois, que a função dialógica da palavra deixa de ser um simples amálgama ou uma reação à palavra do outro, do "já dito", já que está determinada, simultaneamente, pelas formas como se organizam/hegemonizam certas relações de produção em detrimento de outras, segundo os conjuntos de interesses que dominam as formas de organização social e política dos regimes de governo dominantes em cada momento histórico. $\mathrm{O}$ enunciado concreto, dessa forma, somente se realiza sob tais condições. 
Desse modo, a trajetória teórica de Authier-Revuz, na perspectiva de formalizar diferentes modalidades do enunciável, no "fio do discurso", não pode ser tomada como um processo de continuidade das incursões filosóficas de Bakhtin/Volochinov em torno da intervenção da exterioridade sócio-histórica no enunciável. Precisa, segundo nosso ponto de vista, ser apreendida em sua originalidade própria, já que ao afastar-se de pressupostos do materialismo histórico e, ao mesmo tempo, de uma das categorias que afirma privilegiar em seus estudos - a interdiscursividade - tomada de Pêcheux (1988), Authier-Revuz cria uma fronteira entre o processo de investigação das condições históricas de produção do dizer e o processo de descrição das modalidades linguiísticas que atestam, formalmente, o modo como o sujeito se dispersa em seu discurso. Essa compartimentação, por outro lado, não tem "passado em branco" entre os descritivistas e os analistas de discurso. Aos primeiros oferece a possibilidade de reduzir o objeto discursivo à sua materialidade linguística, e aos últimos, a possibilidade de compreensão de que se os sentidos trabalham, produzindo efeitos de deslizamentos semânticos sobre o "já dito", o "já vivido", em última instância impulsionam a desestabilização do próprio modo de funcionamento dos sentidos na linguagem, considerando-se que estes necessitam ser apropriados a partir das relações históricosimbólicas em que se inscrevem para que as materialidades linguiísticas possam ser descritas em suas relações de articulação com os domínios das condições em que emergem nos discursos.

\section{BIBLIOGRAFIA}

ABAEV, V. I. (1969) Modernisme et déshumanisation de la linguistique. Langages: la linguistique en URSS. Paris: Didier/Larousse.

ALTHUSSER, L. (1995) Sur la reproduction. Paris: Presses Universitaires de France.

ARISTÓTELES (1987) Organon: tópicos. Trad. Pinharanda Gomes. Lisboa: Guimarães Edit, v.V. 
Filol. linguiíst. port., n. 9, p. 407-424, 2007.

AUTHIER-REVUZ, J. (2004) Entre a transparência e a opacidade: um estudo enunciativo do sentido. Porto Alegre: EDIPUCRS. Unicamp.

(1998) Palavras incertas. As não-coincidências do dizer. Campinas: Editora da

. (1982) Heterogénéité montrée et heterogenéité constitutive: éléments pour une approche de l'autre dans le discours. DRLAV, 26, p. 91-151.

VOLOCHINOV, V. (1986) Marxismo e filosofia da linguagem. São Paulo: Hucitec.

BAKHTIN, M. (1996) Speech genres and other late essays. Translated by Mc GEE, Vern).Texas: University of Texas Press.

. (1990) Questões de literatura e de estética. A teoria do romance. São Paulo: Hucitec.

DUCROT, O. (1984) Esquisse d'une théorie poliphonique de l'Énonciation. In: Le dire et le dit. Paris: Ed. Minuit [Tradução brasileira: DUCROT, O. (1987) Esboço de uma teoria polifônica da enunciação. In: $O$ dizer e $o$ dito. Campinas: Pontes.

IVANONOVA, I. (2003) Le dialogue dans la linguistique soviétique des annés 1920-1930. Cahiers de I'ILSL: le discours sur la langue em URSS à l'époque stalinienne, 14, p. 157-82.

LACAN, J. (1966) Ecrits. Paris: Seuil.

LÄHTEENMÄKÏ, M. (2005) Estratificação social da linguagem no 'discurso sobre o romance': o contexto soviético oculto. In: ZANDWAIS, A. (org.). Ensaios: Mikhail Bakhtin: contribuições para a Filosofia da Linguagem e estudos discursivos Porto Alegre: Sagra/Luzzatto, p. 41-58.

PÊCHEUX, M. (1988) Semântica e discurso: uma crítica à afirmação do óbvio. Campinas: Editora da Unicamp.

(1980) Remontémonos de Foucault a Spinoza. In: MONTFORTE, M (org.) El discurso político. México: UNAN/Editorial Nueva Imagem, p. 181-97.

SÉRIOT, P. (2005) Bakhtin no contexto: diálogo de vozes e hibridação das línguas. In: ZANDWAIS, A. (org.). Ensaios: Mikhail Bakhtin: contribuições para a Filosofia da Linguagem e estudos discursivos. Porto Alegre: Sagra/Luzzatto, p. 59-72.

TCHOUGOUNNIKOV, S. (2005) Por uma arqueologia dos conceitos do círculo de Bakhtin: ideologema, signo ideológico, dialogismo. In: ZANDWAIS, A. (org.). Ensaios: Mikhail Bakhtin: contribuições para a Filosofia da Linguagem e estudos discursivos. Porto Alegre: Sagra/ Luzzatto, p. 11-40.

. (2001) Lidéologème comme procédé ou la querelle de Bakhtine. Histoire, epistemologie, langage, 2, p.117-42.

ZANDWAIS, A. (2002) As noções de aceitabilidade/justificabilidade no funcionamento argumentativo da linguagem. In: FLORES, V. N.; SILVA, C. L. C. (orgs.). Organon: os estudos enunciativos. Porto Alegre: UFRGS, p. 49-60.

ABSTRACT: This study, developed at the Federal University of Rio Grande do Sul , aims to investigate ways of appropriating some concepts produced by Bakhtin/Volochinov such as 
ZANDWAIS, Ana. Formas de apropriação de concepções de bakhtin/volochinov...

polyphony, ideology and meaning. Our objective is to show how researches developed in the European context can contribute to reveal incongruities in the conceptions of Bakhtin/ Volochinov and in various approaches on their concepts produced outside the soviet/Russian context.

KEYWORDS: Polyphony; utterance; sense. 